\title{
The Risk Evaluation of Tungsten Oxide Nanoparticles in Cultured Rat Liver Cells for Its Safe Applications in Nanotechnology
}

\author{
Hasan Turkez ${ }^{1,2 *}$, Erdal Sonmez ${ }^{2,3}$, Ozlem Turkez ${ }^{4}$, Yousef Ibrahem Mokhtar ${ }^{5}$, Antonio Di \\ Stefano $^{6}$ and Guven Turgut ${ }^{3}$ \\ ${ }^{1}$ Department of Molecular Biology and Genetics; Erzurum Technical University; Erzurum - Turkey. ${ }^{2}$ Department of \\ Nanoscience and Nanoengineering; Advanced Materials Research Laboratory; Graduate School of Natural and \\ Applied Sciences; Atatürk University; Erzurum - Turkey. ${ }^{3}$ Department of Physics, Atatürk University; Erzurum - \\ Turkey. ${ }^{4}$ Department of Biology; Atatürk University; Erzurum - Turkey. ${ }^{5}$ Department of Environmental Studies; \\ Alexandria University; Alexandria - Egypt. ${ }^{6}$ Dipartimento di Farmacia; Università "G. D'Annunzio"; Chieti - Italy
}

\begin{abstract}
Tungsten (VI) oxide ( $\mathrm{WO}_{3}$ ) nanoparticles (NPs) are used for many industrial purposes in everyday life. However, their effects on human health have not been sufficiently evaluated. Therefore, the present study was designed to investigate the toxicity potentials of various concentrations (0 to $1000 \mathrm{ppm})$ of $\mathrm{WO}_{3} \mathrm{NPs}(<100 \mathrm{~nm}$ particle size) in cultured primary rat hepatocytes. The results of cell viability assay showed that the higher concentrations of dispersed $\mathrm{WO}_{3}$ NPs (300, 500 and 1000 ppm) caused significant $(p<0.05)$ decreases of cell viability. Also, dose dependent negative alterations were observed in oxidative status and antioxidant capacity levels after the application of $\mathrm{WO}_{3}$ in cultured rat primary hepatocytes. The results of genotoxicity tests revealed that these NPs did not cause significant increases of micronucleated hepatocytes (MNHEPS) but increased 8-oxo-2-deoxyguanosine (8OH- $d G$ ) levels as compared to the control culture.
\end{abstract}

Key words: tungsten oxide, nanotoxicity, genotoxicity, cytotoxicity, hepatocytes, oxidative stress

\section{INTRODUCTION}

Nanotechnology has emerged to be one of the most powerful technology creating approaches in the past half a century. Nowadays, nanotechnology has spawned the development of a veritable plethora of novel nanoparticles for diverse applications, ranging from solar energy capture to cosmetics and drug delivery (Riehemann et al. 2009; Patel and Patel 2013). With frequent exposure to dispersed nanoparticles from the composite products or workplaces, there is an increased chance for nanoparticles or nano composites to enter human body and to relocate in metabolism-active organs (Song et al. 2009). Thus, studying the toxicity of nanomaterials is of importance to provide the guidance to occupational health and safety (Li et al. 2008; Lanone et al. 2009; Turkez et al. 2013a). The discussion about safety concerns associated with small particles is ongoing for many decades and, to a large extent, is related to the potential risks following inhalative, oral, parenteral or dermal exposure (Schmid et al. 2009). Especially, ultrafine or NPs are in the focus of the debate, e.g.

*Author for correspondence: hasanturkez@gmail.com 
(ECETOC 2005), usually meant to have one or more size dimensions between 0.1 and $100 \mathrm{~nm}$.

In last twenty years, many efforts were made to investigate the toxicity of micro sized natural and man-made mutagens human life and the ability of therapeutic substances on reducing the toxicity of these various toxicants (Turkez et al. 2005; Geyikoglu et al. 2005; Turkez and Geyikoglu 2005; Turkez and Sisman 2007; Turkez et al. 2007; Sisman and Turkez 2010; Rodhger et al. 2012; Turkez and Aydin 2013; Bupesh et al. 2013). But the toxic effects of nano sized particles have not fully studied, except for some inorganic and organic NPs. In fact, a recent report indicated that there was a lack of systematic assessment of the DNA damaging and carcinogenic potential of NPs in spite of their extensive use in nanotechnological applications (Turkez et al. 2013b).

Tungsten (VI) oxide (or tungsten trioxide: $\mathrm{WO}_{3}$ ) is a chemical compound containing oxygen and the transition metal tungsten. It is obtained as an intermediate in the recovery of tungsten from its minerals. Tungsten ores are treated with alkalis for its production. $\mathrm{WO}_{3}$ occurs naturally in the form of hydrates such as tungstite $\left(\mathrm{WO}_{3} \bullet \mathrm{H}_{2} \mathrm{O}\right)$ and meymacite $\left(\mathrm{WO}_{3} \cdot 2 \mathrm{H}_{2} \mathrm{O}\right)$. $\mathrm{WO}_{3}$ is used for many purposes in everyday life. It is frequently used in industry to manufacture tungstates for X-ray screen phosphors, for fireproofing fabrics and in the production of electro chromic windows and gas sensors. Due to its rich yellow color, it is also used as a pigment in ceramics and paints (Erik and Wolf-Dieter 1999; Lee 2000; Pradyot 2003; Merck Index 2006). Tungsten is also used in many military applications since it has the second highest melting temperature of any element. It is generally considered that elucidating the potential health effects of tungsten is important and necessary (Witten et al. 2012). Tungsten (as sodium tungstate) has been found to accumulate in several organs and/or tissues such as kidneys, liver, ovaries, uterus, prostate, pancreas, lung, heart, muscle, spleen and bone following a single oral dose (McInturf et al. 2011). Furthermore neurotoxic (Shan et al. 2012) and dermal toxic (Zhang et al. 2010) effects by tungsten contained NPs have also been reported.

In recent years, tungsten containing nanomaterials due to their big surfaces have attracted a dramatic and exponentially increasing interest in nanotechnological products (Zhou et al. 2012).
Thus, possible health impact of $\mathrm{WO}_{3}$ NPs upon introduction into the body is of great interest. With the increased applications of $\mathrm{WO}_{3} \mathrm{NPs}$, the concerns about their potential human toxicity effects and their environmental impact have also increased. Cytotoxicity, inflammation and increased oxidative stress through reactive oxygen species (ROS) formation are prominently discussed to be relevant factors regarding the safety of small particles down to the nano-range (Knaapen et al. 2004; Unfried et al. 2007; Lewinski et al. 2008; Turkez 2008 and 2011). It has been reported that different sizes and morphologies of NPs have the potential to influence the interaction with many kind of biomolecules, including proteins, enzymes and DNA (Grandjean-Laquerriere et al. 2005; Ramesh et al. 2007; $\mathrm{Xu}$ et al. 2012). The liver was considered as a target site for nanotoxicity due to its accumulative properties after ingestion, inhalation or absorption (Wang et al. 2011). However, recorded hepatotoxicity data for $\mathrm{WO}_{3}$ NPs relating to human health are very scarce.

Since this is considered to be of particular importance for the investigation of mechanisms of ROS formation and oxidative stress, in the present study, specific measurements were performed in the cultured rat primary hepatocytes as in vitro model system for assessing the impact of $\mathrm{WO}_{3}$ NPs on human and environmental health.

\section{MATERIALS AND METHODS}

\section{Synthesis of $\mathrm{WO}_{3} \mathrm{NPs}$}

$\mathrm{Li}_{2} \mathrm{TiO}_{3}$ powder was synthesized via sol-gel route (Poulter and Pryde 1968; Maruyama et al. 1994; Han et al. 1995; Sofian et al. 2007; Ilican et al. 2008; Ghodsi and Absalan 2010) $\mathrm{WO}_{3}$ nanopowders $(<100 \mathrm{~nm})$ were prepared by sol-gel process. The experimental details are shown in Figure 1. Firstly, nitric acid $\left(\mathrm{HNO}_{3}\right)$ solution was added drop-by-drop to sodium tungstate $\left(\mathrm{Na}_{2} \mathrm{WO}_{4} \cdot 2 \mathrm{H}_{2} \mathrm{O}\right)$. Oxalic acid $\left(\mathrm{H}_{2} \mathrm{C}_{2} \mathrm{O}_{4}\right)$ and citric acid $\left(\mathrm{C}_{6} \mathrm{H}_{8} \mathrm{O}_{7}\right)$ were used as complex agents at sol solution. The precipitate obtained was washed several times with absolute ethyl alcohol and dried at $50{ }^{\circ} \mathrm{C}$. The yellow precipitate $\left(\mathrm{WO}_{3}\right)$ powder was produced with calcination at $550{ }^{\circ} \mathrm{C}$ for $3 \mathrm{~h}$. All the chemicals were of analytical grade and supplied by Sigma/Merck. 


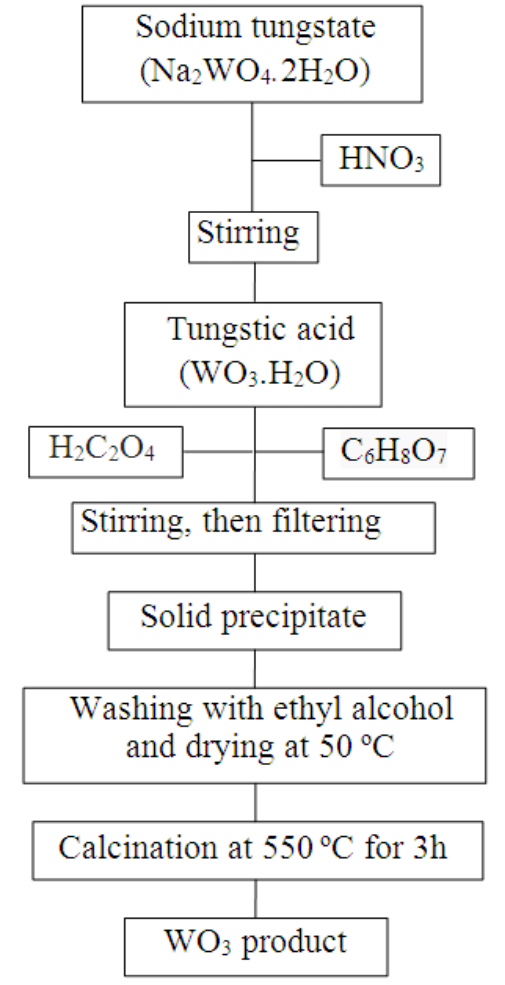

Figure 1 - Schematic diagrams of steps involved in obtaining $\mathrm{WO}_{3}$ powders.

\begin{abstract}
Animals
Male rats of Sprague-Dawley strain (from Medical Experimental Research Center, Atatürk University, Erzurum, Turkey) of 200-300 g body weight, were used throughout the present studies. They were allowed water and standard laboratory chow ad libitum and were maintained under the standard light, temperature, and relative humidity conditions. The study protocol was approved by the local ethical committee. All the experiments were performed in accordance with the Guide for the Care and Use of Laboratory Animals.
\end{abstract}

\section{Hepatocyte isolation and cultivation}

Rats were sacrificed by $\mathrm{CO}_{2}$ overdose and the livers were removed immediately. Isolated hepatocytes from the rats were prepared by the collagenase perfusion technique. The liver was perfused through the hepatic portal vein with calcium-free Hanks balanced salt solution to remove the blood for about $10 \mathrm{~min}$ at a flow rate of $2.5 \mathrm{~mL} \mathrm{~min}{ }^{-1}$. As soon as the liver became grayish brown in color, a second buffer solution containing collagenase (Hank's balanced salt supplemented with $4 \mathrm{mM}$ calcium chloride and 0.5 $\mathrm{mg}$ collagenase $\mathrm{mL}^{-1}$ ) was perfused at the same rate until the liver appeared to have broken up. Then the liver was into 3-4 $\mathrm{mm}$ pieces with a sterile scalpel. Following the mechanical dissociation, the cells were filtered through the gauze and centrifuged at $250 \mathrm{xg}$ for $5 \mathrm{~min}$. Then, the hepatocytes were collected in the medium containing bovine serum albumin and bovine insulin. The cell suspension was filtered through the gauze again and allowed to sediment for 20 min to eliminate cell debris, blood, and sinusoidal cells. The cells were then washed three times by centrifugation at $50 \mathrm{~g}$ and tested by Trypan blue dye exclusion for the viability (always in the range of 82-93\%). The hepatocytes were then suspended in a mixture of $75 \%$ Eagle's minimum essential medium and $25 \%$ medium 199, supplemented with $10 \%$ fetal calf serum containing streptomycin, penicillin, bovine insulin, bovine serum albumin and $\mathrm{NaHCO}_{3}(2.2 \mathrm{mg})$. The hepatocytes were plated in multi-well tissue culture plates $\left(3 \times 10^{5}\right.$ cells in a well area of $3.8 \mathrm{~cm} 2 ; 8 \times 10^{5}$ cells in a well area of $9.6 \mathrm{~cm}^{2}$ ). The medium was changed 3$4 \mathrm{~h}$ later. The effect of $\mathrm{WO}_{3} \mathrm{NPs}$ was studied after $72 \mathrm{~h}$ of exposure in the cultures maintained with a medium deprived of fetal calf serum but supplemented with hydrocortisone hemisuccinate $\left(7 \times 10^{-7} \mathrm{M}\right)$. Hepatocytes were cultured for an additional $8 \mathrm{~h}$ before the treatment.

\section{Treatments}

After $8 \mathrm{~h}$ of plating, when primary hepatocytes were adhered and attained their epithelial morphology, culture medium was aspirated and replaced with an equal volume of the medium supplemented with different concentrations of aqueous $\mathrm{WO}_{3}$ NPs $(5,10,20,50,75,100,150$, 300,500 and $1000 \mathrm{ppm}$ ) followed by incubation in $\mathrm{CO}_{2}$ incubator for $72 \mathrm{~h}(\mathrm{n}=6)$. Mitomycin $\mathrm{C}$ (MMC; $\mathrm{C}_{15} \mathrm{H}_{18} \mathrm{~N}_{4} \mathrm{O}_{5}$; Sigma ${ }^{\circledR}$, at $10^{-7} \mathrm{M}$ ) added group was considered as positive control $\left(\right.$ Control $\left.^{+}\right)$.

\section{MTT assay}

The viability of the cells was assessed by measuring the formation of a formazan from 3-(4,5-dimethylthiazol-2-yl)-2,5-diphenyl tetrazolium bromide (MTT) spectrophotometrically test, modified after Mosmann (1983). Hepatocytes were incubated with $0.7 \mathrm{mg} \mathrm{mL}^{-1} \mathrm{MTT}$ for $30 \mathrm{~min}$ at $37^{\circ} \mathrm{C}$ at the end of the experiment. After washing with PBS, the blue formazan was extracted from the cells with isopropanol/formic acid (95:5) and was 
photometrically determined at $560 \mathrm{~nm}$ (Lewerenz et al. 2003).

\section{LDH assay}

Lactate dehydrogenase (LDH) activity was measured in the culture medium as an index of cytotoxicity, employing an LDH kit (Bayer Diagnostics ${ }^{\circledR}$, France) adapted to the auto analyzer (ADVIA 1650, USA). Enzyme activity was expressed as the extracellular LDH activity percentage of the total activity on the plates.

\section{Total antioxidant capacity and total oxidant status assays}

The automated Trolox equivalent total antioxidant capacity (TAC) and total oxidant status (TOS) assays were carried out in the culture medium by commercially available kits (Rel Assay Diagnostics ${ }^{\circledR}$, Gaziantep, Turkey).

\section{LMN assay}

Liver micronucleus assay (LMN) assay was done by using the method of Suzuki et al. (2009). Immediately prior to the evaluation, $10-20 \mu \mathrm{L}$ of hepatocyte suspension was mixed with an equal volume of acridine orange (AO)-DAPI (4',6diamidino-2-phenylindole dihydrochloride) stain solution (AO, $0.5 \mathrm{mg} \mathrm{mL}^{-1}$; DAPI, $10 \mu \mathrm{g} \mathrm{mL}^{-1}$ ) for fluorescent staining. Approximately $10-20 \mu \mathrm{L}$ of the mixture was dropped onto a glass slide and covered with a cover glass. Samples of wellisolated hepatocytes were evaluated with the aid of a fluorescence microscope counting the number of MNHEPs in 2000 hepatocytes for each animal. MNHEPs were defined as hepatocytes with round or distinct MNs that stained like the nucleus, with a diameter $1 / 4$ or less than that of the nucleus, and confirmed by focusing up and down, taking into account hepatocyte thickness by one observer.

\section{Nucleic acid oxidation}

DNA oxidation was determined by measuring the amount of 8-OH-dG adducts. DNA was digested by incubation with DNAase I, endonuclease, and alkaline phosphatase (Schneider et al. 1993). The amount of $8-\mathrm{OH}-\mathrm{dG}$ was measured by highperformance liquid chromatography (HPLC) with electrochemical detection as described previously (Floyd et al. 1993).

\section{Statistical analysis}

The experimental data were analyzed using oneway analysis of variance (ANOVA) and Fischer's least significant difference (LSD) tests to determine whether any treatment significantly differed from the controls or each other's. Results were presented as the mean $\pm \mathrm{SD}$ values and the level of 0.05 was regarded as statistically significant.

\section{RESULTS}

The results of cell viability measured by the MTT assay are shown in Figure 2. When assayed in vitro on the hepatocyte cells using the MTT assay, the value for the MMC-treated cells (as control ${ }^{+}$) was approximately 2.4-fold lower than that for the control. Similarly, the higher concentrations of $\mathrm{WO}_{3}$ NPs $(300,500$ and $1000 \mathrm{ppm})$ caused significant $(\mathrm{p}<0.05)$ decreases of the cell viability. However, the hepatocyte cells exposed to lower doses than $300 \mathrm{ppm}$ of $\mathrm{WO}_{3} \mathrm{NPs}$ did not show any significant change in cell viability during $72 \mathrm{~h}$ as determined by the MTT assay. No cytotoxicity was observed for the control ${ }^{-}$cells. MMC-induced hepatic damage was clearly evidenced by 6 -fold increases in the activity of LDH compared with the observations of the negative controls (Fig. 3). Although LDH was not affected by the low doses of $\mathrm{WO}_{3} \mathrm{NPs}$ alone, but the increases of the levels of enzyme reached statistical significances at 300 , 500 and $1000 \mathrm{ppm}$.

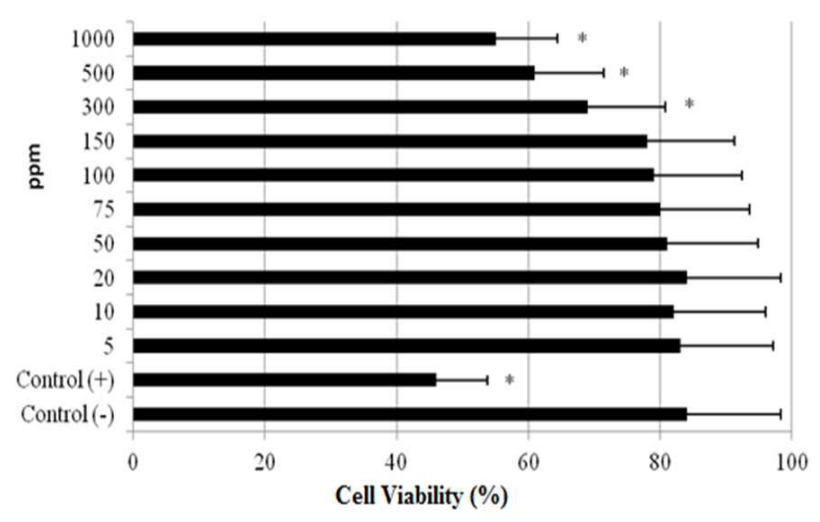

Figure 2 - MTT reduction [3-(4,5-dimethyl-thiazol-2yl) 2,5-diphenyltetrazolium bromide] in cultured rat hepatocytes maintained in the presence of different $\mathrm{WO}_{3} \quad$ NPs concentrations for $72 \mathrm{~h}$.

(Each individual hepatocyte culture without NPs was studied as a negative control group (Control'). MMC alone added group was considered as a positive control $\left(\mathrm{Control}^{+}\right)$. Values are means \pm standard deviation $(\mathrm{n}=$ 6). * symbol presents significant differences at the $\mathrm{p}<0.05$ level from the control ${ }^{-}$group). 


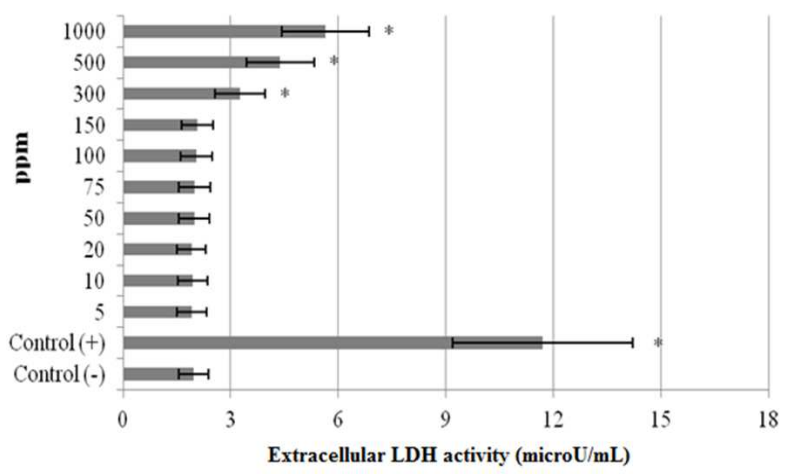

Figure 3 - Extracellular level of lactate dehydrogenase $(\mathrm{LDH})$ in cultured rat hepatocytes maintained in the presence of different WO3 NPs concentrations for $72 \mathrm{~h}$. Each individual hepatocyte culture without NPs was studied as a negative control group (Control -). MMC alone added group was considered as a positive control (Control + ). Values are means \pm standard deviation $(\mathrm{n}=$ 6). * symbol presents significant differences at the $\mathrm{p}<0.05$ level from the control group).

The levels of 8-oxo-2-deoxyguanosine (8-OH-dG) in the cultured rat hepatocytes of controls and experimental groups are shown in Figure 4. Firstly, the levels of 8-OH-dG, a sensitive marker of oxidative DNA damage, were quantified with regard to MMC treatment. It was observed that MMC significantly increased 8-OH-dG concentrations in the hepatocyte cultures after 72 h. Similarly, 8-OH-dG levels increased in the hepatocyte cells that were treated with 500 and $1000 \mathrm{ppm}$ of $\mathrm{WO}_{3} \mathrm{NPs}$.

The results of the observed LMN rates in the primary rat hepatocyte cells after $72 \mathrm{~h} \mathrm{WO}_{3} \mathrm{NPs}$ treatment are presented in Figure 5. LMN analyses did not show statistically significant differences ( $>>0.05$ ) between the control ${ }^{-}$and tested NPs applied cultures.

Table 1 showed the effects of $\mathrm{WO}_{3} \mathrm{NPs}$ on oxidant status in the cultured rat hepatocytes, which were determined by the TAC and TOS analysis. The TAC value decreased with the addition of MMC while TOS value increased. In contrast to the treatments with $5,10,20,50,75$ and $100 \mathrm{ppm}$ of $\mathrm{WO}_{3}$, NPs did not alter the TAC and TOS levels. However, nanomaterials applications at higher doses $(150,300,500$ and $1000 \mathrm{ppm})$ changed the TAC and TOS levels. Thus, $\mathrm{WO}_{3}$ NPs had dose dependent effects on the oxidative damage in hepatocytes in vitro.

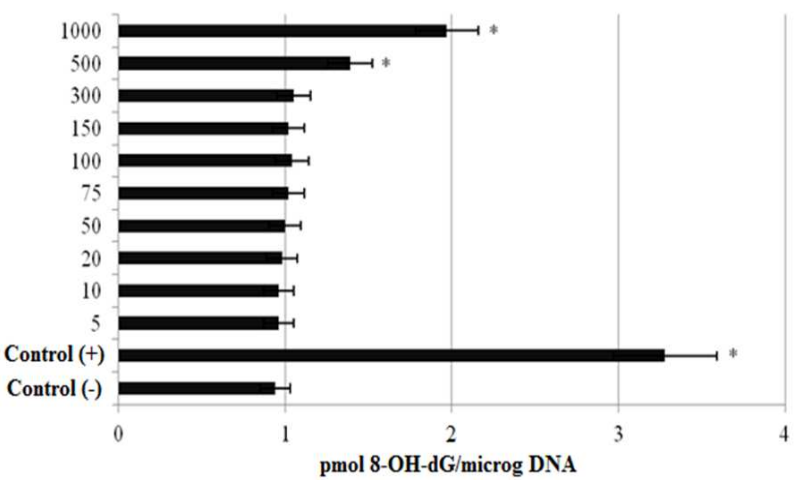

Figure 4 - 8-oxo-2-deoxyguanosine (8-OH-dG) adducts in cultured rat hepatocytes maintained in the presence of different WO3 NPs concentrations for $72 \mathrm{~h}$. Each individual hepatocyte culture without NPs was studied as a negative control group (Control -). MMC alone added group was considered as a positive control (Control + ). Values are means \pm standard deviation $(n=6)$. ${ }^{*}$ symbol presents significant differences at the $\mathrm{p}<0.05$ level from the control - group).

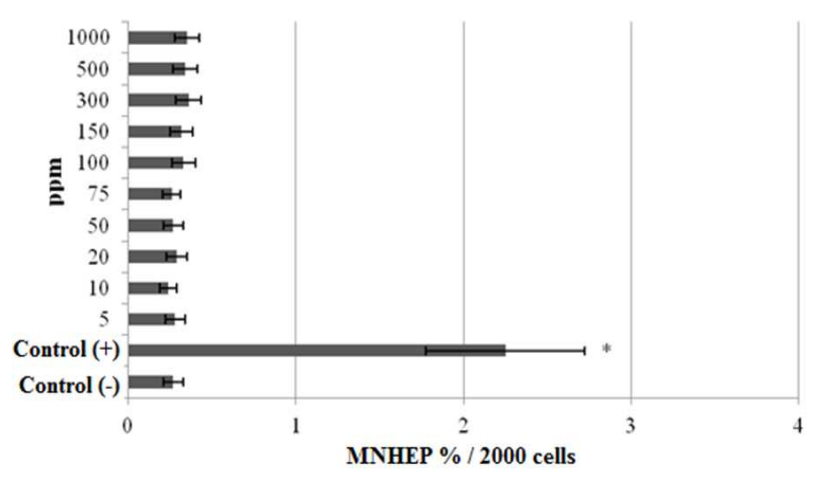

Figure 5 - Results of liver MN assay in cultured rat hepatocytes maintained in the presence of WO3 NPs for $72 \mathrm{~h}$. HEP = hepatocyte; MNHEP $=$ Number of micronucleated hepatocytes. Each individual hepatocyte culture without NPs was studied as a negative control group (Control -). MMC alone added group was considered as a positive control (Control +$)$. Values are means \pm standard deviation $(\mathrm{n}=6)$. * symbol presents significant differences at the $\mathrm{p}<0.05$ level from the control - group). 
Table 1 - Extracellular TAC and TOS levels in cultured rat hepatocytes maintained with $\mathrm{WO}_{3}$ NPs for $72 \mathrm{~h}$. Each individual hepatocyte culture without NPs was studied as a negative control group (Control -). Ascorbic acid (10 ?M) and hydrogen peroxide (25 ?M) added groups were also used as the control+ in TAC and TOS analysis, respectively. Values are means \pm standard deviation $(n=6)$. * symbol presents significant differences at the $\mathrm{p}<0.05$ level from the control group).

\begin{tabular}{lcc} 
Treatment & $\begin{array}{c}\text { TAC (mmol } \\
\text { Trolox Equiv./I) }\end{array}$ & $\begin{array}{c}\text { TOS }(\boldsymbol{\mu m o l ~ H 2 O 2 ~} \\
\text { Equiv./I) }\end{array}$ \\
\hline Control $^{-}$ & $3.9 \pm 0.9$ & $9.1 \pm 2.9$ \\
Control $^{+}$ & $2.1 \pm 0.7^{*}$ & $16.5 \pm 3.4^{*}$ \\
$5 \mathrm{ppm}$ & $3.9 \pm 0.8$ & $9.3 \pm 3.3$ \\
$10 \mathrm{ppm}$ & $3.8 \pm 0.9$ & $9.2 \pm 3.4$ \\
$20 \mathrm{ppm}$ & $3.8 \pm 1.1$ & $9.4 \pm 3.7$ \\
$50 \mathrm{ppm}$ & $3.6 \pm 1.1$ & $9.6 \pm 4.0$ \\
$100 \mathrm{ppm}$ & $3.4 \pm 1.3$ & $9.6 \pm 3.6$ \\
$150 \mathrm{ppm}$ & $3.1 \pm 0.9^{*}$ & $10.8 \pm 4.1^{*}$ \\
$300 \mathrm{ppm}$ & $2.7 \pm 1.3^{*}$ & $12.9 \pm 4.2^{*}$ \\
$500 \mathrm{ppm}$ & $2.6 \pm 0.7^{*}$ & $13.4 \pm 4.5^{*}$ \\
$1000 \mathrm{ppm}$ & $2.6 \pm 1.1^{*}$ & $14.2 \pm 4.4^{*}$ \\
\hline
\end{tabular}

\section{DISCUSSION}

In the present investigation, it was aimed to evaluate the cytotoxicity, genotoxicity and oxidative damage in the cultured rat healthy hepatocyte cells in response to different concentrations of $\mathrm{WO}_{3}$ NPs. Trends in the cytotoxicity as observed for the different concentrations of these NPs were overall highly similar using the two independent assays (MTT and $\mathrm{LDH}$ ) in the cultured rat hepatocytes. A particular contrast was observed for the highest concentrations of $\mathrm{WO}_{3} \mathrm{NPs}$, which induced a pronounced LDH release and decrease of MTT. As a matter of fact, tungsten carbide nanoparticles (WC NPs) caused reduction in cell viability between 10 and 50\% compared to controls upon particle exposure in the rainbow trout (Oncorhynchus mykiss) gill cell line, RTgill-W1 (Kühnel et al. 2009). Rothen-Rutishauser et al. (2007) reported that the size of nano-particles or their aggregates could be considered a potential determinant for the uptake and subsequent macrophage responses, which could explain the observed differences on LDH release at the highest concentration of NPs (Albrecht et al. 2009). Particles in the fine size range may induce more pronounced responses than in the nano-range (Rothen-Rutishauser et al. 2007), and the "ultrafine hypothesis" has been challenged previously by the experimental studies (Schins et al. 2004). Albrecht et al. (2009) found that cytotoxicity as observed at high concentrations did not necessarily represent a compound-related effect, and could at least partly be due to physical coverage of the cells by the test NPs.

The fully understanding of how $\mathrm{WO}_{3}$ NPs interact with hepatocytes, especially at the molecular level, is still unclear. Present findings demonstrated that direct exposure of the hepatocytes to $\mathrm{WO}_{3} \mathrm{NPs}$ induced the intracellular ROS generation, reduced the total antioxidant capacity (TAC), increased 8$\mathrm{OH}-\mathrm{dG}$ levels, and subsequently caused dysfunction of these cells. In accordance with the present results, it has been reported that engineered nanomaterials, either metals (like carbon and silver) or metal oxides (like zinc oxide, magnesium oxide, and titanium oxide), induce toxicity and oxidative stress by generating free radicals (Turkez and Geyikoglu 2007; Anreddy et al. 2013). Mechanisms involved in the reduction of cell viability through oxidative stress by $\mathrm{WO}_{3} \mathrm{NPs}$ are not yet known. Oxidative stress is associated with protein and lipid oxidation, ultimately leading to a profound alteration in mitochondrial function (Pan et al. 2009). Any change in the mitochondrial membrane permeability is known to be an early event in apoptosis (Liu and Sun 2010). It is known that ROS activates multiple signaling pathways, including mitogen activated protein kinase (MAPK) family and p53 expression signal transduction cascades (Simbula et al. 2007). P53, $\mathrm{Bax}$ and $\mathrm{Bcl}-2$ are also generally thought to be involved in mitochondria-dependent apoptosis (Liu and Sun 2010). p-JNK, p-c-Jun, p-p53, Bax, cleaved caspase- 3 were significantly increased in the human umbilical vein endothelial cells (HUVECs) after exposure to silica nanoparticles, while Bcl-2 was dramatically suppressed. ROS scavenger could markedly inhibit the JNK, c-Jun and p53 activity, indicating that ROS could be upstream effectors of JNK and p53 (Liu and Sun 2010). Hsin et al. (2008) found that nano silverinduced apoptosis was mediated by the ROS via JNK and p53 activation. ROS could also directly activate $\mathrm{p} 53$, most probably by the induction of DNA damage (Simbula et al. 2007; Turkez and Togar 2010; Turkez and Geyikoglu 2010; Turkez et al. 2012). Based on the results of Liu and Sun (2010), the following silica nanoparticles-mediated signaling pathways for apoptosis related events were proposed as ROS production (JNK/c-Jun 
phosphorylation), P53 activation, Bax up regulation and $\mathrm{Bcl}-2$ down regulation.

Previous studies showed that higher dose exposure to nanomaterials, including silica nanoparticles, titanium dioxide, zinc oxide, alumina nanoparticles led to proinflammatory and procoagulant responses in endothelial cells. It is an accepted view point that ROS are involved in many of the processes underlying endothelial activation (e.g., the up regulation of adhesion molecules and chemokines, increased expression of tissue factor). Many of the key signal transduction molecules involved in the endothelial activation, such as various MAPKs and the transcription factors NF-kB, are known to be redox sensitive (Alom-Ruiz et al. 2008). To assess the biological effect of different concentrations of $\mathrm{WO}_{3} \mathrm{NPs}$ on rat hepatocyte cells, cell viability was determined. In the present study, MTT and LDH assays showed that the higher concentrations of $\mathrm{WO}_{3}$ NPs decreased cell viability. Also, Liu and Sun (2010) found that exposure to high concentrations (100-200 ppm) of silica nanoparticles caused an increase of cytotoxicity in HUVECs. The LDH release was also increased by silica nanoparticles only at the highest concentration, indicating that exposure to high concentrations of silica nanoparticles could affect cell-membrane integrity and lead to cell death. They also reported the induction of apoptosis or necrosis by silica nanoparticles and oxidative stress as silica nanoparticles induced toxicity mechanism. Liu and Sun (2010) showed that intracellular ROS generation of HUVECs by silica nanoparticles was gradually increased in a timeand dose-dependent manner, suggesting that oxidative stress occurred not at once, but continuously during the cell culture. ROS played a central role in silica nanoparticles-mediated apoptosis. Disturbance of membrane integrity has been recently suggested as possibly one of the mechanisms for cytotoxic action in the nanoparticles (Kim et al. 2009). In accordance to the present findings, the results by Ding et al. (2009) had demonstrated that nano-WC-Co generated a higher level of hydroxyl radicals, induced greater oxidative stress, as evidenced by a decrease of glutathione (GSH) levels.

Present results indicated that $\mathrm{WO}_{3} \mathrm{NPs}$ did not induce the LMN formations in in vitro conditions. The study of DNA damage at the chromosome level is an essential part of genotoxicity testing because chromosomal mutation is an important event in carcinogenesis. LMN assays have emerged as one of the preferred methods for assessing the chromosome damage because they enable both chromosome loss and chromosome breakage to be measured reliably. The NPs, which were located in the cytosol near the nucleus but not were found inside the nucleus, in mitochondria or ribosomes did not induce DNA-breakage (Bhattacharya et al. 2009). But $\mathrm{WO}_{3} \mathrm{NPs}$ led to oxidative DNA damages as determined by the increases of $8-\mathrm{OH}-\mathrm{dG}$ levels, which were the major products of DNA oxidation in present study. Thus, apparently $\mathrm{WO}_{3}$ NPs were not clastogenic but were able to generate elevated amounts of free radicals, which induced indirect genotoxicity, mainly by DNA-adduct formation. In contrast to our in vitro findings, $\mathrm{WO}_{3} \mathrm{NPs}$ showed positive mutagenic response in TA1537 and TA98 bacterial strains of Salmonella typhimurium by using Ames test (Hasegawa et al. 2012). $\mathrm{WO}_{3} \mathrm{NPs}$ did not cause increase of the incidence of chromosome aberrations in rat bone marrow cells but led to increases of MN formation after chronic exposure for 30 days (Turkez et al. 2013a). These conflicting evidences on genotoxicity by $\mathrm{WO}_{3} \mathrm{NPs}$ could be explained by the differences in conditions (in vivo or in vitro), exposuring time (acute, chronic or sub chronic) and chemical features of tested NPs (exact size, shape, composition, and aggregation). It is known that studies dealing with nanotoxicity have focused on in vitro cell culture studies. However, data obtained from such studies might not correspond to in vivo results. Hence, a full in vivo life cycle characterization framework would be necessary for systematic evaluation of the size, shape, and surface chemistry of NPs, and their correlation to in vivo behavior. In vivo systems were extremely complicated and the interactions of NPs with biological components, such as proteins and cells could lead to unique biodistribution, clearance, immune response, and metabolism (Fischer and Chan 2007; Berger 2008).

In summary, data from the current study showed that exposure to $\mathrm{WO}_{3} \mathrm{NPs}$ at high concentrations caused ROS generation and decreased the total antioxidant capacity (TAC) in cultured primary rat hepatocytes. NPs caused decreased cell viability, which was detected by the increased MTT and $\mathrm{LDH}$ release. The present findings also showed that $\mathrm{WO}_{3} \mathrm{NPs}$ had weak genotoxic potential in vitro. Overall, these findings suggested that 
exposure to $\mathrm{WO}_{3} \mathrm{NPs}$ could pose environmental and human health risk.

\section{REFERENCES}

Albrecht C, Scherbart AM, van Berlo D, Braunbarth CM, Schins RPF, Scheel J. Evaluation of cytotoxic effects and oxidative stress with hydroxyapatite dispersions of different physicochemical properties in rat NR8383 cells and primary macrophages. Toxicol In Vitro. 2009; 23: 520-530.

Alom-Ruiz SP, Anilkumar N, Shah AM. Reactive oxygen species and endothelial activation. Antioxid Redox Signal. 2008; 10: 1089-1100.

Anreddy RN, Yellu NR, Devarakonda KR. Oxidative biomarkers to assess the nanoparticle-induced oxidative stress. Methods Mol Biol. 2013; 1028: 205219.

Berger M. Nanotechnology and toxicity: the growing need for in vivo study. http://www.nanowerk.com. 2008.

Bhattacharya K, Davoren M, Boertz J, Schins RP, Hoffmann E, Dopp E. Titanium dioxide nanoparticles induce oxidative stress and DNA-adduct formation but not DNA-breakage in human lung cells. Part Fibre Toxicol. 2009; 6: 17.

Bupesh G, Chinnaiah A, Sakthivel V, Natesan M, Ramalingam SR, Raju K, Periyasamy S. Hepatoprotective efficacy of Hypnea muciformis ethanolic extract on $\mathrm{CCl} 4$ induced toxicity in rats. Braz Arch Biol Technol. 2012; 55: 857-863.

Ding M, Kisin ER, Zhao J, Bowman L, Lu Y, Jiang B, Leonard S, Vallyathan V, Castranova V, Murray AR, Fadeel B, Shvedova AA. Size-dependent effects of tungsten carbide-cobalt particles on oxygen radical production and activation of cell signaling pathways in murine epidermal cells. Toxicol Appl Pharmacol. 2009; 241: 260-268.

ECETOC. Workshop on Testing Strategies to Establish the Safety of Nanomaterials. November 2005, Barcelona, Workshop Report No: 7.

Erik L, Wolf-Dieter S. Tungsten: properties, chemistry, technology of the element, alloys, and chemical compounds. 1999; Kluwer Academic, USA.

Fischer HC, Chan WCW. Nanotoxicity: the growing need for in vivo study. Curr Opinion Biotechnol. 2007; 18: 565-571.

Floyd RA, Watson JJ, Wong PK, Altmiller DH, Rickard RC. Hydroxyl free radical adduct of deoxyguanosine: Sensitive detection and mechanisms of formation. Free Radic Res Commun. 1993; 1: 163172.

Geyikoglu F, Turkez H. Protective effect of sodium selenite on genotoxicity to human whole blood cultures induced by aflatoxin B-1. Braz Arch Biol Technol. 2005; 48: 905-910.
Ghodsi FE, Absalan H. Comparative study of ZNO thin films prepared by different sol-gel route. Acta Phys Pol A. 2010; 118: 659-664.

Grandjean-Laquerriere A, Laquerriere P, Guenounou M, Laurent-Maquin D, Phillips TM. Importance of the surface area ratio on cytokines production by human monocytes in vitro induced by various hydroxyapatite particles. Biomater. 2005; 26: 23612369.

Han SD, Campet G, Huang SY, Shasrty MCR, Portier J. A new method for the preparation of fine-grained $\mathrm{SnO} 2$ and WO3 powders: influence of the crystallite size on the electrochemical insertion of $\mathrm{Li}+$ in $\mathrm{SnO} 2$ and WO3 electrodes. Active Passive Electron Component. 1995; 18: 39-51.

Hasegawa G, Shimonaka M, Ishihara Y. Differential genotoxicity of chemical properties and particle size of rare metal and metal oxide nanoparticles. J Appl Toxicol. 2012; 32: 72-80.

Hsin YH, Chen CF, Huang S, Shih TS, Lai PS, Chueh PJ. The apoptotic effect of nanosilver is mediated by a ROS- and JNK-dependent mechanism involving the mitochondrial pathway in NIH3T3 cells. Toxicol Lett. 2008; 179: 130-139.

Hoshino T, Tanaka K, Makita J, Hashimoto T. Investigation of phase transition in $\mathrm{Li} 2 \mathrm{TiO} 3$ by high temperature X-ray diffraction. J Nuclear Mater. 2007; 367: 1052-1056.

Ilıcan S, Caglar Y, Caglar M. Preparation and characterization of $\mathrm{ZnO}$ thin films deposited by solgel spin coating method. J Optoelectron Adv Mater. 2008; 10: 2578-2583.

Jian-wen Y, Hui Z, Haryun Z, Yarryang D, Jian L, Xuan Z. Synthesis and electrochemical properties of nanocrystalline $\mathrm{Li}[\mathrm{Li} 1 / 3 \mathrm{Ti} / 5 \mathrm{O} 4]$ by complex sol-gel method. Trans Nonferrous Met Soc China. 2004; 14: 1012-1016.

Kim S, Choi JE, Choi J, Chung KH, Park K, Yi J. Oxidative stress-dependent toxicity of silver nanoparticles in human hepatoma cells. Toxicol In Vitro. 2009; 23: 1076-1084.

Knaapen AM, Borm PJ, Albrecht C, Schins RP. Inhaled particles and lung cancer. Part A: Mechanisms. Int J Cancer. 2004; 109:799-809.

Kühnel D, Busch W, Meissner T, Springer A, Potthoff A, Richter V. Agglomeration of tungsten carbide nanoparticles in exposure medium does not prevent uptake and toxicity toward a rainbow trout gill cell line. Aquat Toxicol. 2009; 93: 91-99.

Lanone S, Rogerieux F, Geys J, Dupont A, MaillotMarechal E, Boczkowski J. Comparative toxicity of 24 manufactured nanoparticles in human alveolar epithelial and macrophage cell lines. Part Fibre Toxicol. 2009; 6: 14-19.

Lee WJ. Effects of surface porosity on tungsten trioxide (WO3) films' electrochromic performance. J Electron Mater. 2000; 29: 183-187. 
Lewerenz V, Hanelt S, Nastevska C, El-Bahay C, Rohrdanz E, Kahl R. Antioxidants protect primary rat hepatocyte cultures against acetaminophen-induced DNA strand breaks but not against acetaminopheninduced cytotoxicity. Toxicol. 2003; 191: 179-187.

Lewinski N, Colvin V, Drezek R. Cytotoxicity of nanoparticles. Small. 2008; 4: 26-49.

Li SQ, Zhu RR, Zhu H, Xue M, Sun XY, Yao SD, Wang SL. Nanotoxicity of $\mathrm{TiO}(2)$ nanoparticles to erythrocyte in vitro. Food Chem Toxicol. 2008; 46: 3626-3631.

Liu X, Sun J. Endothelial cells dysfunction induced by silica nanoparticles through oxidative stress via JNK/P53 and NF-kB pathways. Biomater. 2010; 31: 8198-8209.

McInturf SM, Bekkedal MYV, Wilfong E, Arfsten D, Chapman G, Gunasekar PG. The potential reproductive, neurobehavioral and systemic effects of soluble sodium tungstate exposure in SpragueDawley rats. Toxicol Appl Pharmacol. 2011; 254: 133-137.

Maruyama T, Arai S. Electrochromic properties of tungsten trioxide thin films prepared by chemical vapor deposition. Phys Inorg Chem. 1994; 25: 31005.

Merck Index. Tungsten trioxide. 2006; Vol. 14.

Mosmann T. Rapid colorimetric assay for cellular growth and survival: application to proliferation and cytotoxicity assay. J Immunol Meth. 1983; 65: 55-63.

Pan Y, Leifert A, Ruau D, Neuss S, Bornemann J, Schmid G. Gold nanoparticles of diameter $1.4 \mathrm{~nm}$ trigger necrosis by oxidative stress and mitochondrial damage. Small. 2009; 5: 2067-2076.

Patel DJ and Patel JK. Design and evaluation of famotidine mucoadhesive nanoparticles for aspirin induced ulcer treatment. Braz Arch Biol Technol. 2013; 56: 223-236.

Poulter KF, Pryde JA. Chemisorption of hydrogen on rhenium. Brit J Appl Phys Ser. 1968; 1: 169.

Pradyot P. Handbook of inorganic chemical compounds. 2003; ISBN. 0-07-049439-8. McGrawHill, USA, p. 1086.

Ramesh M, Turner LF, Yadav R, Rajan TV, Vella AT, Kuhn LT. Effects of the physico-chemical nature of two biomimetic crystals on the innate immune response. Int Immunopharmacol. 2007; 7: 1617-1629.

Riehemann K, Schneider SW, Luger TA, Godin B, Ferrari M, Fuchs H. Nanomedicine-challenge and perspectives. Angew Chem Int Ed Engl. 2009; 48: 872-897.

Rothen-Rutishauser B, Mühlfeld C, Blank F, Musso C, Gehr P. Translocation of particles and inflammatory responses after exposure to fine particles and nanoparticles in an epithelial airway model. Part Fibre Toxicol. 2007; 4: 9.
Rodgher S, Espindole ELG, Simoes FCF, Tonietto AE. Cadmium and chromium toxicity to Pseudokirchneriella subcapitata and Microcystis aeruginosa. Braz Arch Biol Technol. 2012; 55: 161169.

Schins RP, Lightbody JH, Borm PJ, Shi T, Donaldson $\mathrm{K}$, Stone V. Inflammatory effects of coarse and fine particulate matter in relation to chemical and biological constituents. Toxicol Appl Pharmacol. 2004; 195: 1-11.

Schmid O, Moller W, Semmler-Behnke M, Ferron GA, Karg E, Lipka J. Dosimetry and toxicology of inhaled ultrafine particles. Biomarkers. 2009; 14: 67-73.

Schneider JE, Jr Phillips JR, Pye Q, Maidt ML, Price S, Floyd RA. Methylene blue and rose bengala photoinactivation of RNA bacteriophages: Comparative studies of 8-oxoguanine formation in isolated RNA. Arch Biochem Biophys. 1993; 301: 91-97.

Shan D, Xie Y, Ren G, Yang Z. Inhibitory effect of tungsten carbide nanoparticles on voltage-gated potassium currents of hippocampal CA1 neurons. Toxicol Lett. 2012; 209: 129-135.

Simbula G, Columbano A, Ledda-Columbano GM, Sanna L. Increased ROS generation and p53 activation in alpha-lipoic acidinduced apoptosis of hepatoma cells. Apoptosis. 2007; 12: 113-123.

Sisman T, Turkez H. Toxicologic evaluation of imazalil with particular reference to genotoxic and teratogenic potentials. Toxicol Ind Health. 2010; 26: 641-648.

Sofian MK, Carl PT. Synthesis, FTIR studies and sensor properties of WO3 powders. Curr Opin Solid State Mater Sci. 2007; 11: 19-27.

Song $\mathrm{Y}, \mathrm{Li} \mathrm{X}, \mathrm{Du} \mathrm{X}$. Exposure to nanoparticles is related to pleural effusion, pulmonary fibrosis and granuloma. Eur Respir J. 2009; 34: 559-567.

Tsuchiya K, Nakamichi M, Nagao Y, Enoeda M. In-situ tritium recovery experiments of blanket in-pile mockup with $\mathrm{Li}_{2} \mathrm{TiO}_{3}$ pebble bed in Japan. J Nuclear Sci Technol. 2001; 38: 996-999.

Turkez H, Cakmak B, Celik K. Evaluation of the potential in vivo genotoxicity of tungsten (VI) oxide nanopowder for human health. Key Engineering Mater. 2013a; 543: 89-92.

Turkez H, Celik K, Cakmak B. Biosafety evaluation of nanoparticles in view of genotoxicity and carcinogenicity studies: A systematic review. Key Engineering Mater. 2013b; 543: 200-203.

Turkez H, Aydin E. The Genoprotective Activity of resveratrol on permethrin-induced genotoxic damage in cultured human lymphocytes. Braz Arch Biol Technol. 2013; 56: 405-411. 
Turkez H, Geyikoglu F, Tatar A, Keles MS, Kaplan I. The effects of some boron compounds against heavy metal toxicity in human blood. Exp Toxicol Pathol. 2012; 64: 93-101.

Turkez H. The role of ascorbic acid on titanium dioxide-induced genetic damage assessed by the comet assay and cytogenetic tests. Exp Toxicol Pathol. 2011; 63: 453-457.

Turkez H, Togar B. The genotoxic and oxidative damage potential of olanzapine in vitro. Toxicol Ind Health. 2010; 26: 583-588.

Turkez H, Geyikoglu F. Boric acid: a potential chemoprotective agent against aflatoxin $b(1)$ toxicity in human blood. Cytotechnol. 2010; 62: 157-165.

Turkez H. Effects of boric acid and borax on titanium dioxide genotoxicity. J Appl Toxicol. 2008; 28: 658664.

Turkez H, Geyikoglu F, Tatar A, Keleş S, Ozkan A. Effects of some boron compounds on peripheral human blood. Z Naturforsch C. 2007; 62: 889-896.

Turkez H, Sisman T. Anti-genotoxic effect of hydrated sodium calcium aluminosilicate on genotoxicity to human lymphocytes induced by aflatoxin B1. Toxicol Ind Health. 2007; 23: 83-89.

Turkez H, Geyikoglu F, Keles MS. Biochemical response to colloidal bismuth subcitrate: dose-time effect. Biol Trace Elem Res. 2005; 105: 151-158.

Turkez H, Geyikoglu F. An in vitro blood culture for evaluating the genotoxicity of titanium dioxide: the responses of antioxidant enzymes. Toxicol Ind Health. 2007; 23:19-23.
Unfried K, Albrecht C, Klotz LO, Mikecz von A, Grether-Beck S, Schins RPF. Cellular responses to nanoparticles: target structures and mechanisms. Nanotoxicol. 2007; 1: 52-71.

Wang Y, Aker WG, Hwang HM, Yedjou CG, Yu H, Tchounwou PB. A study of the mechanism of in vitro cytotoxicity of metal oxide nanoparticles using catfish primary hepatocytes and human HepG2 cells. Sci Total Environ. 2011; 409: 4753-4762.

Witten ML, Sheppard PR, Witten BL. Tungsten toxicity. Chem Biol Interact. 2012; 196: 87-88.

$\mathrm{Xu} \mathrm{Z}$, Zhang YL, Song $\mathrm{C}$, Wu LL, Gao HW. Interactions of hydroxyapatite with proteins and its toxicological effect to zebrafish embryos development. PLoS One. 2012; 7: e32818.

Zhang XD, Zhao J, Bowman L, Shi X, Castranova V, Ding M. Tungsten carbide-cobalt particles activate Nrf2 and its downstream target genes in JB6 cells possibly by ROS generation. J Environ Pathol Toxicol Oncol. 2010; 29: 31-40.

Zhou G, Hou Y, Liu L, Liu H, Liu C, Liu J, Qiao H, Liu W, Fan Y, Shen S, Rong L. Preparation and characterization of NiW-nHA composite catalyst for hydrocracking. Nanoscale. 2012; 4: 7698-7703.

Received: June 24, 2013; Accepted: January 30, 2014. 